\title{
Sexual violence in older adults: a Belgian prevalence study
}

Anne Nobels ${ }^{1,2^{*}}$, Adina Cismaru-Inescu ${ }^{3,4+}$, Laurent Nisen ${ }^{3}$, Bastien Hahaut ${ }^{3}$, Marie Beaulieu ${ }^{5}$, Gilbert Lemmens ${ }^{2,6}$, Stéphane Adam ${ }^{4}$, Evelyn Schapansky ${ }^{7}$, Christophe Vandeviver ${ }^{7,8 \neq}$ and Ines Keygnaert ${ }^{1}$

\begin{abstract}
Background: Sexual violence (SV) is an important public health problem which may cause long-lasting health problems. SV in older adults remains neglected in research, policies and practices. Valid SV prevalence estimates and associated risk factors in older adults are currently unavailable. In this study we measured lifetime and past 12months sexual victimisation in older adults living in Belgium, its correlates, assailant characteristics and the way that victims framed their SV experiences.

Methods: SV was measured using behaviourally specific questions based on a broad definition of SV. Participants were selected via a cluster random probability sampling with a random route finding approach. Information on sexual victimisation, correlates, assailant characteristics and framing was collected via structured face-to-face interviews with adults aged 70 years and older living in Belgium (community-dwelling, assisted living and nursing homes).

Results: Among the 513 participants, the lifetime SV prevalence was 44\% (55\% F, 29\% M). Past 12-months prevalence was $8 \%(9 \% \mathrm{~F}, 8 \% \mathrm{M})$. Female sex and a higher number of sexual partners were associated with lifetime SV $(p<.05)$, non-heterosexual sexual orientation with past 12-months SV $(p<.05)$. Correlates identified to be linked to elder abuse and neglect in previous studies were not linked with SV in our sample. 'Someone unknown' was identified as most common assailant.

Conclusions: Sexual victimisation appears to be common in older adults in Belgium. Both correlates and assailant characteristics seem to differ from previous studies on elder abuse and neglect. Recognizing older adults as a risk group for sexual victimisation in research, policies and practices is of the utmost importance.
\end{abstract}

Keywords: Sexual abuse, Sexual assault, Elder abuse and neglect, Ageing

\section{Background}

Sexual violence (SV) [1] is increasingly considered a public health problem of major societal and judicial concern $[2,3]$. Extensive research links sexual victimisation to long-lasting sexual, reproductive, physical, and mental

\footnotetext{
* Correspondence: anne.nobels@uzgent.be

${ }^{\dagger}$ Adina Cismaru-Inescu is shared first author.

${ }^{\ddagger}$ Christophe Vandeviver is shared last author.

IInternational Centre for Reproductive Health, Department of Public Health and Primary Care, Ghent University, Ghent, Belgium

2Department of Psychiatry, Ghent University Hospital, Ghent, Belgium

Full list of author information is available at the end of the article
}

health problems [2-4]. Exposure to childhood sexual abuse has been linked to depression, anxiety, and somatic complaints in older adults $[5,6]$.

Previous research suggests that SV in older adults rarely occurs [7]. A recent meta-analysis showed that $0.9 \%$ of community-dwelling older adults worldwide were sexually victimised in the past 12-months [8]. In Europe, numbers of past 12-months SV prevalence in older adults varied between 0 and 3.1\% [9]. In a Belgian study, lifetime SV prevalence was estimated at 6.3\% [10]. However, current studies show low SV prevalence

(c) The Author(s). 2021, corrected publication 2021. Open Access This article is licensed under a Creative Commons Attribution 4.0 International License, which permits use, sharing, adaptation, distribution and reproduction in any medium or format, as long as you give appropriate credit to the original author(s) and the source, provide a link to the Creative Commons licence, and indicate if changes were made. The images or other third party material in this article are included in the article's Creative Commons licence, unless indicated otherwise in a credit line to the material. If material is not included in the article's Creative Commons licence and your intended use is not permitted by statutory regulation or exceeds the permitted use, you will need to obtain permission directly from the copyright holder. To view a copy of this licence, visit http://creativecommons.org/ licenses/by/4.0/. The Creative Commons Public Domain Dedication waiver (http://creativecommons.org/publicdomain/zero/1. 0/) applies to the data made available in this article, unless otherwise stated in a credit line to the data. 
numbers as they conflate it with other types of violence in the broader context of elder abuse and neglect [9], domestic violence or intimate partner violence [11]. Studies exclusively focussing on SV in older adults, describe criminal cases, and judicial response [12, 13]. Yet, research on SV in older adults from a public health perspective, providing valid SV prevalence numbers and correlates, is currently lacking. Several risk factors have been associated with elder abuse and neglect, such as poor (perceived) health status, care dependency, low social support, and financial strain [14-19]. However, specific risk factors for sexual violence in old age are currently unknown [9].

Assessing sexual victimisation in older adults may be challenging for myriad reasons. Older adults grew up in a time when talking about sexuality and SV was considered taboo. They may also have different perceptions of sexuality and SV compared to younger generations [20], because of limited sexual education when they were young, different legal definitions and ideas on sexual consent [21, 22]. Furthermore, older adults are considered asexual by society [23]. Internalizing this stereotypical image of 'the asexual older adult', they may not identify themselves as possible SV victims [24, 25], which could lead to a reluctance to disclose sexual victimisation, and to seek help [26, 27]. Moreover, health care workers feel that sexuality and SV are not legitimate topics to discuss with older adults and are worried to offend their patients when they do so $[28,29]$. Also, they seem to have insufficient communication skills to adequately deal with SV in later life [28].

In spite of the call by the United Nations to significantly reduce all forms of violence [29], policies on SV in older adults are currently non-existent [9]. In order to develop preventive measures and to provide tailored care for older SV victims, a revision of current policies and health care practices is of the utmost importance $[9,30]$. To make this possible, a better understanding of the prevalence and nature of SV in older adults is crucial. To our knowledge, this study is the first in its kind to assess lifetime and past 12-months sexual victimisation, correlates, assailant characteristics and the way that older victims framed their SV experiences. Based on the results, we identify avenues for future research, and formulate recommendations for policies and health care practices.

\section{Methods}

\section{Measures}

We adopted the WHO definition of SV, which includes different forms of sexual harassment without physical contact (hands-off SV), sexual abuse with physical contact but without penetration and (attempted) rape (hands-on SV) [1, 3]. This definition was expanded to include sexual neglect, as a result of recent insights in the field of SV in older adults [9, 31]. In 2017, a group of scientists, professionals and policy makers from Quebec, Canada, defined sexual neglect as 'a failure to provide privacy, a failure to respect a person's sexual orientation or gender identity, treating older adults as asexual beings and/ or preventing them from expressing their sexuality, etc.' [31].

This study was a part of a national SV prevalence study in the Belgian population between 16 and 100 years old. We used the same questionnaire across all ages. The questionnaire development comprised a multi-step process of discussion and consultation between the multidisciplinary research team and an expert steering committee consisting of national and international researchers, policy makers and practitioners in the field of SV or elder abuse and neglect. An extensive description of the validation of the questionnaire in the Belgian population, including older adults, is available elsewhere [32, 33]. Moreover, we conducted a two-phase pilot study to test the acceptability and feasibility of the questionnaire in older adults. More details on this pilot study were published elsewhere [34]. Participants were asked, among others, questions on sociodemographic characteristics, sexual health \& relations and sexual victimisation. In order to provide valid estimates of both female and male sexual victimisation, we used behaviourally specific questions (BSQ) to assess lifetime and past 12months SV experiences [35]. The SV items were based on existing surveys [36-38], and adapted to the Belgian social and legal context [32, 33]. Due to the absence of a standardised measure for sexual neglect, it was assessed as "touching in care" (see Appendix 1). Participants who indicated to have experienced lifetime SV, were asked further questions on the assailant(s) and how they framed their sexual violence experience(s). For hands-off SV questions were asked for the behaviour that impacted the victim the most. For hands-on SV, these questions were asked for each of the SV behaviours. Moreover, for each hands-on SV behaviour, victims were asked to indicate the types of coercion strategies that were used. The questions on assailants, framing and coercion strategies are available in Appendices 2, 3 and 4.

\section{Sample selection}

Between the 8th July 2019 and the 12th March 2020, 513 older adults across Belgium were interviewed. Based on our power analysis, the target sample size was 845 participants [34]. It was anticipated this sample size would provide a SV prevalence estimate with a $3 \%$ margin of error. However, the COVID-19 pandemic and associated lockdown measures forced us to prematurely stop data collection. Cluster random probability 
sampling was used to obtain representative results for the Belgian older population. Eligible participants were identified using a random walk procedure [34, 39]. Participants had to be at least 70 years old, live in Belgium, speak Dutch, French or English, and have sufficient cognitive ability to complete the interview. Cognitive status was assessed based on the ability to maintain attention during the interview and the consistency of the participant's answer, by means of a control question comparing the participant's birth year and age. Both older adults living in the community and living in nursing homes or assisted living facilities were included. Face-to-face interviews were carried out by trained interviewers in private at the participant's place of residence.

The study was conducted according to the Declaration of Helsinki and the WHO ethical and safety recommendations for SV research [40], and received ethical approval from the ethical committee of Ghent University/University Hospital (Belgian reference number: B670201837542). All participants gave their written informed consent before participating in the study. After participation they were given the contact details of several helplines. Participation rate was $34 \%$. The full study protocol is available elsewhere [34].

\section{Analyses}

Statistical analysis was performed using $\mathrm{R}$ version 3.6.3 and SPSS Statistics 26. The 17 SV variables were grouped into hands-off (eight items) and hands-on SV (nine items), the latter being further grouped into sexual abuse (four items) and attempted or completed rape (five items). For the purpose of the analysis the item measuring sexual neglect was grouped under sexual abuse. We created dichotomous variables out of all items in order to assess lifetime and past 12-months victimisation. A detailed overview of the SV outcome measures can be found in Appendix 1.

A number of demographic and socio-economic variables and variables related to the participants' sexual health and relations were included in the multivariate logistic regression analysis. All variables were added simultaneously. Adjusted odds ratios describe the correlation with sexual victimisation while adjusting for the other variables in the model. The multi-collinearity assumption of multivariate regression analyses was tested with the Variance Inflation Factor (VIF) and indicated no violation. Social support (measured by number of confidants) could be added as a continuous variable into the model without violating the linearity assumption. The number of lifetime sexual partners and age of sexual initiation were recoded into dichotomous variables based on the median.

\section{Results}

\section{Study population characteristics}

The study sample consisted of a valid representation of the Belgian population aged 70 years and older [34]. The mean age was 79 years (SD: 6.4 yrs., range $70-99$ yrs), $58.3 \%$ was female, $89.8 \%$ was community-dwelling, 90.4\% was born in Belgium, 31.2\% completed higher education, $50.3 \%$ was in a relationship and $7.4 \%$ labelled themselves as non-heterosexual. This group contains participants who labelled themselves as homosexual, bisexual, pansexual, asexual or other. In this last group, several participants labelled themselves as "normal". Since it was not clear whether they had difficulties understanding the different terms defining sexual orientation or whether they indeed labelled their sexual orientation as "other", we decided to classify these participants as non-heterosexual. More information on the sample composition in comparison to the Belgian population of 70 years and older can be found in Appendix 5 .

\section{Prevalence of sexual victimisation}

The lifetime prevalence of SV was $44.2 \%$ (95\% CI: $39.9-$ 48.7), $55.2 \%$ (95\% CI: $49.4-60.9$ ) of females and $29.0 \%$ (95\% CI: 23.0-35.5) of males. Almost half of women and one in four men experienced hands-off SV, one in three women and one in six men reported hands-on SV. One in twelve females and one in 30 males disclosed an (attempted) rape. In the past 12-months, $8.4 \%$ (95\% CI: 6.1-11.1) experienced at least one form of SV, $9 \%$ of females and $7.5 \%$ of males. Hands-off SV was reported by $7.7 \%$ of females and $6.1 \%$ of males, hands-on SV by $2.7 \%$ of females and $2.3 \%$ of males. The most commonly reported sexually transgressive behaviours were unwanted sexual staring, sexual innuendo and kissing; both during lifetime and in the past 12-months.

A more detailed description of the prevalence of all different forms of SV can be found in Table 1.

\section{Coercion strategies}

Figure 1 shows the types of coercion used by the assailants for the different types of hands-on lifetime SV. Over one third of the victims indicated that none of the provided response options applied to their situation. For (attempted) rape specifically, (threat of) using physical force was the most commonly identified coercion strategy.

\section{Characteristics of SV victims}

Table 2 summarizes the results of the logistic regression analysis. Women were more likely to be sexually victimised in their lifetime, but for the past 12-months we found no difference between women and men regarding sexual victimisation. Participants with two or more lifetime sexual partners experienced more SV in their life 
Table 1 Detailed lifetime and past 12-months prevalence sexual victimisation, by sex

\begin{tabular}{|c|c|c|c|c|c|c|}
\hline \multirow[b]{2}{*}{ Item } & \multicolumn{2}{|l|}{$\begin{array}{l}\text { Men } \\
(n=214)\end{array}$} & \multicolumn{2}{|l|}{$\begin{array}{l}\text { Women } \\
(n=299)\end{array}$} & \multicolumn{2}{|l|}{$\begin{array}{l}\text { Total } \\
(n=513)\end{array}$} \\
\hline & $\begin{array}{l}\text { Lifetime } \\
\%(95 \% \mathrm{Cl})\end{array}$ & $\begin{array}{l}\text { Past 12-months } \\
\%(95 \% \mathrm{Cl})\end{array}$ & $\begin{array}{l}\text { Lifetime } \\
\%(95 \% \mathrm{Cl})\end{array}$ & $\begin{array}{l}\text { Past 12-months } \\
\%(95 \% \mathrm{Cl}) \\
\end{array}$ & $\begin{array}{l}\text { Lifetime } \\
\%(95 \% \mathrm{Cl})\end{array}$ & $\begin{array}{l}\text { Past 12-months } \\
\%(95 \% \mathrm{Cl})\end{array}$ \\
\hline Any SV & $29.0(23.0-35.5)$ & $7.5(4.3-11.9)$ & $55.2(49.4-60.9)$ & $9.0(6.0-12.9)$ & $44.2(39.9-48.7)$ & $8.4(6.1-11.1)$ \\
\hline Any Hands-Off SV & $22.4(17.0-28.6)$ & $6.1(3.3-10.2)$ & $45.2(36.4-51.0)$ & $7.7(4.9-11.3)$ & $35.7(31.5-40.0)$ & $7.0(5.0-9.6)$ \\
\hline Sexual staring & $11.2(7.3-16.2)$ & $2.3(0.8-5.4)$ & $23.7(19.0-29.0)$ & $2.7(1.2-5.2)$ & $18.5(15.2-22.2)$ & $2.5(1.4-4.3)$ \\
\hline Sexual innuendo & $7.0(4.0-11.3)$ & $3.3(1.3-6.6)$ & $22.4(17.8-27.6)$ & $3.0(1.4-5.6)$ & $16.0(12.9-19.5)$ & $3.1(1.8-5.0)$ \\
\hline Showing sexual images & $5.1(2.6-9.1)$ & $2.3(0.8-5.4)$ & $6.4(3.9-9.7)$ & $0.7(0.1-2.4)$ & $5.9(4.0-8.3)$ & $1.4(0.6-2.8)$ \\
\hline Sexual calls or texts & $4.2(1.9-7.8)$ & $1.4(0.3-4.0)$ & $8.0(5.2-11.8)$ & $1.3(0.4-3.4)$ & $6.5(4.5-9.0)$ & $1.4(0.6-2.8)$ \\
\hline Voyeurism & $0.5(0.0-2.6)$ & $0.0(0.0-1.7)$ & $0.3(0.0-1.9)$ & $0.0(0.0-1.2)$ & $0.4(0.0-1.4)$ & $0.0(0.0-0.7)$ \\
\hline Distributing sexual images & $0.0(0.0-1.7)$ & $0.0(0.0-1.7)$ & $0.0(0.0-1.2)$ & $0.0(0.0-1.2)$ & $0.0(0.0-0.7)$ & $0.0(0.0-0.7)$ \\
\hline Exhibitionism & $5.6(2.9-9.6)$ & $1.4(0.3-4.0)$ & $20.7(16.3-25.8)$ & $1.7(0.5-3.9)$ & $14.5(11.5-17.8)$ & $1.6(0.7-3.0)$ \\
\hline $\begin{array}{l}\text { Forcing to show intimate } \\
\text { body parts }\end{array}$ & $1.9(0.5-4.8)$ & $0.0(0.0-1.7)$ & $3.0(1.4-5.6)$ & $0.7(0.1-2.4)$ & $2.5(1.4-4.3)$ & $0.4(0.0-1.4)$ \\
\hline Any Hands-On SV & $15.9(11.3-21.5)$ & $2.3(0.8-5.4)$ & $35.1(29.7-40.8)$ & $2.7(1.2-5.2)$ & $27.1(23.3-31.2)$ & $2.5(1.4-4.3)$ \\
\hline Any Sexual Abuse & $13.6(9.3-18.9)$ & $2.3(0.8-5.4)$ & $33.8(28.4-39.4)$ & $2.3(0.9-4.8)$ & $25.3(21.6-29.3)$ & $2.3(1.2-4.1)$ \\
\hline Kissing & $8.9(5.4-13.5)$ & $1.9(0.5-4.7)$ & $21.1(16.6-26.6)$ & $1.7(0.5-3.9)$ & $16.0(12.9-19.4)$ & $1.8(0.8-3.3)$ \\
\hline Touching in care & $0.9(0.1-3.3)$ & $0.5(0.0-2.6)$ & $5.4(3.1-8.5)$ & $0.7(0.1-2.4)$ & $3.5(2.1-5.5)$ & $0.6(0.1-1.7)$ \\
\hline Fondling/rubbing & $6.1(3.3-10.2)$ & $1.9(0.5-4.7)$ & $16.4(12.4-21.1)$ & $1.7(0.5-3.9)$ & $12.1(9.4-15.2)$ & $1.8(0.8-3.3)$ \\
\hline Forced undressing & $1.9(0.5-4.7)$ & $1.9(0.5-4.7)$ & $3.0(1.4-5.6)$ & $1.7(0.5-3.9)$ & $2.5(1.4-4.3)$ & $1.8(0.8-3.3)$ \\
\hline Any Rape & $3.3(1.3-6.6)$ & $0.0(0.0-1.7)$ & $8.4(5.5-12.1)$ & $1.0(0.2-2.9)$ & $6.2(4.3-8.7)$ & $0.6(0.1-1.7)$ \\
\hline Oral penetration & $0.5(0.0-2.6)$ & $0.0(0.0-1.7)$ & $1.7(0.5-3.9)$ & $0.0(0.0-1.2)$ & $1.2(0.4-2.5)$ & $0.0(0.0-0.7)$ \\
\hline Attempt of oral penetration & $1.4(0.3-4.0)$ & $0.0(0.0-1.7)$ & $3.3(1.6-6.1)$ & $0.3(0.0-1.8)$ & $2.5(1.4-4.3)$ & $0.2(0.0-1.1)$ \\
\hline Vaginal or anal penetration & $0.9(0.1-3.3)$ & $0.0(0.0-1.7)$ & $4.3(2.3-7.3)$ & $0.3(0.0-1.8)$ & $2.9(1.6-4.8)$ & $0.2(0.0-1.1)$ \\
\hline Attempt of vag. or anal penetr. & $0.9(0.1-3.3)$ & $0.0(0.0-1.7)$ & $2.0(0.7-4.3)$ & $0.3(0.0-1.8)$ & $1.6(0.7-3.1)$ & $0.2(0.0-1.1)$ \\
\hline Forcing to penetrate & $0.0(0.0-1.7)$ & $0.0(0.0-1.7)$ & $0.3(0.0-1.8)$ & $0.0(0.0-1.2)$ & $0.2(0.0-1.1)$ & $0.0(0.0-0.7)$ \\
\hline
\end{tabular}

Abbreviations: SV Sexual Violence, CI Confidence Interval

\section{Coercion strategies}

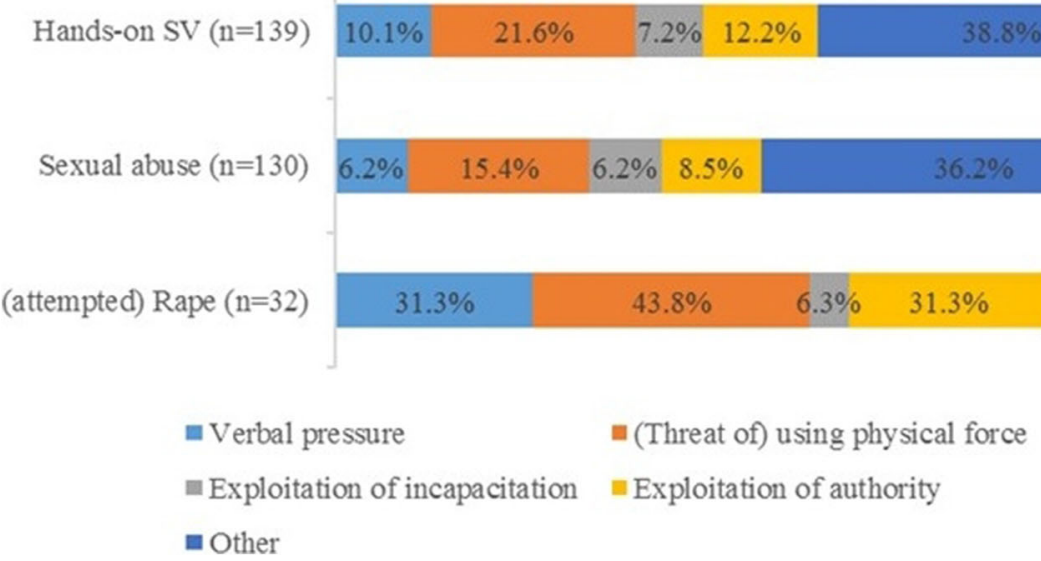

Fig. 1 Type of coercion used for hands-on lifetime sexual violence, sexual abuse, and (attempted) rape. Note. Respondents could provide multiple answers, unless "Other" = None of the above was selected. Abbreviations: SV = sexual violence 
Table 2 Sexual victimisation correlates

\begin{tabular}{|c|c|c|c|}
\hline Predictors & & $\begin{array}{l}\text { Lifetime SV } \\
\text { aOR }(95 \% \mathrm{Cl})\end{array}$ & $\begin{array}{l}\text { Past 12-months SV } \\
\text { aOR }(95 \% \mathrm{Cl})\end{array}$ \\
\hline \multirow[t]{2}{*}{ Sex } & Female & $3.60(2.35-5.52) *$ & $1.57(0.74-3.34)$ \\
\hline & Male & Ref & Ref \\
\hline \multirow[t]{3}{*}{ Perceived age } & Younger & $1.43(0.87-2.36)$ & $0.85(0.36-2.00)$ \\
\hline & Same & Ref & Ref \\
\hline & Older & $0.85(0.29-2.46)$ & / \\
\hline \multirow[t]{2}{*}{ Sexual orientation } & Heterosexual & Ref & Ref \\
\hline & Non-heterosexual & $0.80(0.38-1.70)$ & $3.23(1.17-8.94) *$ \\
\hline \multirow[t]{3}{*}{ Living situation } & Community-dwelling & Ref & Ref \\
\hline & Assisted living & $2.01(0.78-5.20)$ & $0.97(0.20-4.62)$ \\
\hline & Nursing home & $0.70(0.26-1.91)$ & $0.94(0.19-4.85)$ \\
\hline \multirow[t]{3}{*}{ Relationship status } & No partner & Ref & Ref \\
\hline & Not living with partner & $0.96(0.62-1.49)$ & $0.51(0.23-1.14)$ \\
\hline & Living with partner & $0.67(0.30-1.53)$ & $0.21(0.03-1.69)$ \\
\hline \multirow[t]{3}{*}{ Education level } & Primary or none & $0.75(0.44-1.29)$ & $0.60(0.24-1.52)$ \\
\hline & Secondary & $0.87(0.55-1.36)$ & $0.54(0.25-1.19)$ \\
\hline & Higher & Ref & Ref \\
\hline \multirow[t]{2}{*}{ Financial status } & Easy & Ref & Ref \\
\hline & Difficult & $1.02(0.66-1.60)$ & $0.67(0.29-1.55)$ \\
\hline \multirow[t]{2}{*}{ Care dependency } & No & Ref & Ref \\
\hline & Yes & $1.04(0.68-1.59)$ & $0.91(0.43-1.94)$ \\
\hline Social support & & $1.01(0.99-1.04)$ & $1.00(0.96-1.04)$ \\
\hline \multirow[t]{2}{*}{ Perceived health status } & No disability/chronical illness & Ref & Ref \\
\hline & Disability/chronical illness & $0.96(0.64-1.45)$ & $0.84(0.41-1.74)$ \\
\hline \multirow[t]{2}{*}{ Sexual initiation ${ }^{a}$} & Early (<21 years) & $1.25(0.84-1.86)$ & $1.16(0.56-2.39)$ \\
\hline & Late ( $\geq 21$ years) & Ref & Ref \\
\hline \multirow[t]{2}{*}{$N$ of lifetime sexual partners ${ }^{a}$} & $<2$ & Ref & Ref \\
\hline & $\geq 2$ & $1.54(1.01-2.34)^{*}$ & $1.93(0.92-4.04)$ \\
\hline
\end{tabular}

Abbreviations: SV Sexual violence, $a O R$ adjusted odds ratio

${ }^{*} p<.05$

${ }^{a}$ Sexual initiation and number of lifetime sexual partners were dichotomized based on the median

compared to participants with fewer than two sexual partners. This difference was not significant in the past 12-months. Regarding sexual orientation, we found that older adults who identified themselves as nonheterosexual experienced significantly more SV in the past 12-months. However, for lifetime SV this difference was not significant.

\section{Assailant characteristics}

For lifetime SV, $83.6 \%$ of assailants were male, $15.0 \%$ were female, and in $1.4 \%$ of the cases the sex of the assailant was unknown. In the past 12 -months, $73.3 \%$ of assailants were male, $24.4 \%$ were female and in $0.2 \%$ of the cases the sex of the assailant was unknown. Mean age of the assailant committing SV in the past 12months, as estimated by the victim, was 48.9 years (SD
18.9 yrs). For both lifetime and past 12-months SV 'someone unknown' was most often identified as the assailant, respectively in 41.4 and $44.2 \%$ of the cases. More details on the relationship between victim and assailant can be found in Fig. 2.

\section{Framing of sexual violence by victims}

Table 3 summarizes how victims of lifetime SV framed their experience(s). In $47.6 \%$ of the cases, SV was framed as 'just something that happened', in $34.4 \%$ as 'wrong, but not a crime' and in $23.3 \%$ as a crime. Concerning rape, we found that in $28.1 \%$ of cases victims framed it as 'just something that happened', in $28.1 \%$ as 'wrong, but not a crime', and in $43.8 \%$ as a crime. 


\section{Relationship with assailant}

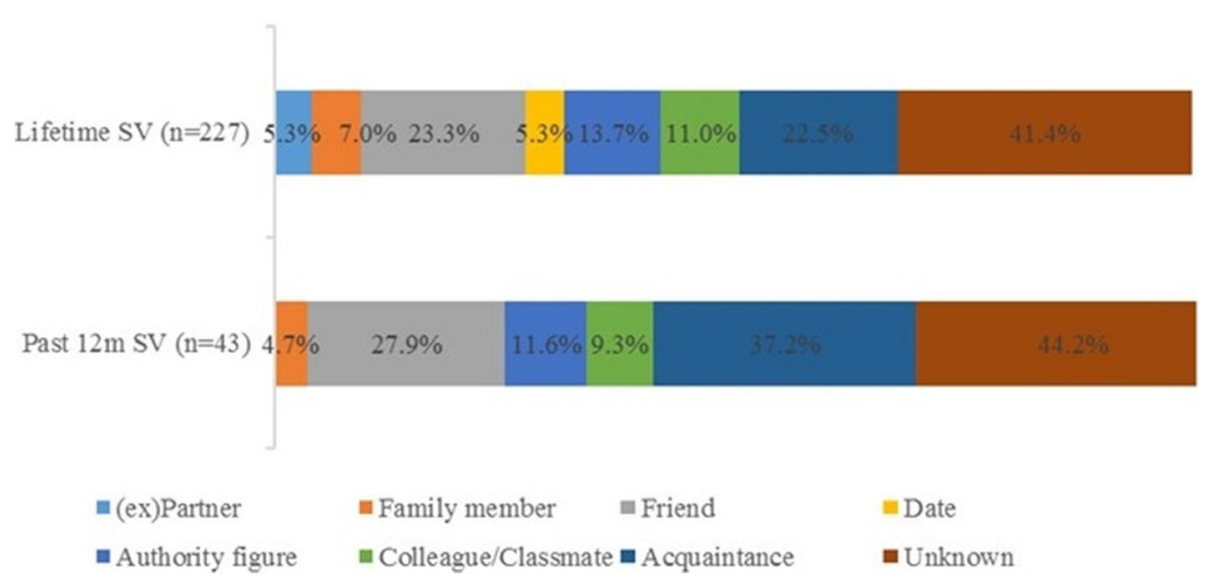

Fig. 2 Relationship between victim and assailant of sexual violence, in \%. Note. Participants could provide multiple answers. Abbreviations: $\mathrm{SV}=$ sexual violence, past $12 \mathrm{~m}=$ past 12 -months

\section{Discussion}

In this paper we present a Belgian prevalence study on sexual victimisation in older adults. We conducted 513 interviews with people aged 70 years and older across Belgium.

Our results show that lifetime exposure to SV is highly prevalent among older adults in Belgium. Over $44 \%$ of participants were sexually victimized during their lifetime. Despite the assumption that older adults are at low risk for sexual victimisation [7], in our study, one in 12 older adults experienced at least one form of SV in the past 12-months. Our numbers appear higher compared to previous European studies in community-dwelling older adults in which the estimated lifetime SV prevalence was $6.3 \%$ and the past 12 -months prevalence rates varied between 0 and $3.1 \%[9,10]$. This difference could be explained by several methodological choices. First, we studied SV in older adults from a different perspective compared to previous studies that researched SV based on criminal cases $[12,13]$ or as a form of elder abuse and neglect, domestic violence or intimate partner violence $[9,11]$. Hence, they restricted the relation between victim and assailant to a confidant, a household member or an intimate partner respectively while our research shows that assailants are also unknown. Moreover, previous research only included forms of hands-on SV (sexual abuse with physical contact and (attempted) rape). Applying the broad WHO definition of SV, we included both hands-off and hands-on SV regardless of the relation between victim and assailant, leading to increased lifetime and past 12-months SV prevalence numbers. Second, the use of the BSQ made it easier for participants to remember and engage with the situations presented. Furthermore, BSQ leave less room for interpretation, stigma or labelling which makes it possible for people who do not identify as a victim to indicate their SV experiences, leading to more valid estimates [35].

However, compared to an online study in the Belgian population aged 16 to 69 years using the same questionnaire, we found lower lifetime and past 12-months prevalence rates [32]. This decreased SV reporting with increasing age may adequately represent lower sexual victimisation rates in older adults or may be explained

Table 3 Framing of lifetime sexual violence by victims

\begin{tabular}{|c|c|c|c|}
\hline & $\begin{array}{l}\text { A Crime } \\
\text { n (\%) }\end{array}$ & $\begin{array}{l}\text { Wrong but not a crime } \\
\text { n (\%) }\end{array}$ & $\begin{array}{l}\text { Just something that happened } \\
\mathrm{n}(\%)\end{array}$ \\
\hline Any SV $(n=227)$ & $53(23.3)$ & $78(34.4)$ & $108(47.6)$ \\
\hline Any hands-off $(n=183)$ & $34(18.6)$ & $53(23.0)$ & $72(26.8)$ \\
\hline Any hands-on $(n=139)$ & $34(24.5)$ & $42(38.1)$ & $49(51.8)$ \\
\hline Sexual Abuse $(n=130)$ & $27(20.8)$ & $47(36.2)$ & $68(52.3)$ \\
\hline (attempted) Rape $(n=32)$ & $14(43.8)$ & $9(28.1)$ & $9(28.1)$ \\
\hline
\end{tabular}

Note. For hands-off SV only the incident with the most impact on the victim was included in the analysis. For hands-on SV all incidents were included and grouped into sexual abuse, (attempted) rape and hands-on SV. If victims indicated a different framing for different incidents, they are included as separate answers and so the total $\%$ is $>100 \%$

Abbreviations: SV = sexual violence 
by several factors, such as reduced recall in general [41], reduced recall of negative events [42, 43], or higher mortality among people with a SV history [44, 45]. Moreover, older adults might have a different perception of SV than younger generations. In our study, in $47.6 \%$ of SV cases and in $28.1 \%$ of rape cases, victims perceived it as 'just something that happened'. Previous studies found that generational specificities surrounding sexuality and SV such as legal definitions and perceptions of SV, influenced disclosure rates [13, 46]. Furthermore, society's attitudes regarding sexuality have become more permissive, and the definition of sexual consent has been narrowed [20]. For example, until the end of the twentieth century being married implied consent to sexual intercourse, whereas today spousal rape is considered a criminal offence [21]. In our study, in only $5.3 \%$ of lifetime SV cases, the (ex) partner was identified as assailant, which is much less compared to studies in younger populations in which over $25 \%$ of women indicated being sexually victimised by their (ex) partner [47]. Finally, because of the image of 'the asexual older adult '[23], older adults might not identify themselves as a victim of SV $[24,25]$. In previous studies on elder abuse and neglect, older adults did not acknowledge SV as a possible form of abuse [48]. To a certain extent, we have preemptively addressed this by adopting BSQ to measure sexual victimisation, as BSQ allow victims who do not identify themselves as such to indicate their experiences [35]. Nevertheless, such beliefs may have inadvertently influenced SV disclosure in our study.

In addition to measuring SV prevalence, our study aimed to provide an analysis of SV correlates in older adults. Correlates linked to elder abuse and neglect in previous studies, such as poor (perceived) health status, care dependency, low social support, and financial strain [14-19], were not associated with sexual victimisation in our sample. We assume this can be explained by the use of a broad definition of SV including both hands-off and hands-on SV, which is different from the definitions used in studies on elder abuse and neglect. Moreover, there is a possible underpower of our sample which could explain the low number of correlates identified. Being female and having a greater number of lifetime sexual partners were associated with lifetime sexual victimisation, which is in line with previous research on SV in younger populations [37, 49]. For past 12 -months SV, we could not identify a difference between men and women. Previous research showed inconclusive results. Although some studies described older women as being more prone to SV [50,51], others showed that women and men were equally at risk $[52,53]$. In our sample, being non-heterosexual was correlated to past 12-months SV. Previous research has linked LGBT+ status, often intertwined with other factors such as disability and poverty, to intimate partner violence among older adults [54], but for SV this has not been reported before. However, our results have to be interpreted with caution as a possible difficulty of several participants to understand the different terms defining sexual orientation, could lead to an overestimation of non-heterosexual people in our sample. Furthermore, our results confirm previous findings that assailants of SV in older adults tend to be younger than the victim [50].

Regarding coercion strategies, we found that the (threat of) using physical force was the most common coercion used for any type of rape. For any type of sexual abuse, over one third of the participants indicated that none of the mentioned types of coercion were used. This suggests our study did not capture all types of coercion strategies used in hands-on SV [32, 33]. A recent study by Canan et al. [55] in victims from 23 to 68 years old identified more coercion strategies, such as 'making me feel as though refusing was useless' and 'just doing the behaviour without giving me a chance to say "no" (e.g., surprising me with the behaviour).' More research is needed to check whether these coercion strategies can be extrapolated to SV in old age. Previous studies showed inconclusive results regarding coercion strategies. Although some studies reported physical force was more often used on older SV victims compared to younger victims, most studies did not report significant differences between younger and older victims regarding use of physical force as a coercion strategy [12]. Because our findings are similar to the coercion strategies identified by younger victims in Belgium [32], we assume that the coercion strategies used on older adults are similar to the ones used on younger victims and not as violent as believed [12].

An important limitation of our study was that the target sample size of 845 interviews could not be reached due to the COVID-19 pandemic and associated lockdown measures. However, the current sample size of 513 interviews allowed us to report on prevalence rates within $4 \%$ of the estimated value. Furthermore, due to the absence of a standardised measure for sexual neglect, we narrowed it down to "touching in care" which is an incomplete representation of the definition [31] and supposed reality. Nevertheless, this study is, to our knowledge, the first of its kind to measure the prevalence, correlates, assailant characteristics and framing of SV in older adults. It can be regarded as an important step towards a better understanding of the magnitude, nature and impact of SV in older adults. Responding to the call of Bows [12] to consider SV as a particular form of violence in old age and study it independently from other forms of elder abuse and neglect and domestic violence, this study brings a new perspective on SV in older adults. For future studies, we encourage the 
development of measurement tools for sexual neglect in order to incorporate this form of SV as well.

Based on our findings we reinforce previous recommendations for policy makers to recognise older adults as a risk group for sexual victimisation [12]. Furthermore, our study showed that assessing SV in older adults is possible without offending them [34]. Professionals urgently need capacity building to better detect signs, prevent, mitigate and respond to SV in old age. Finally, sensitisation of society in general is essential, emphasizing the prevention of SV against older adults.

\section{Conclusions}

Sexual victimisation appears to be common in older adults in Belgium. Over 44\% experienced SV in their lifetime and one in 12 in the past 12-months. Being female and having had a greater number of lifetime sexual partners were linked to lifetime SV, a non-heterosexual sexual orientation to past 12 -months victimisation. Correlates generally linked to elder abuse and neglect did not seem to be linked with SV. Our findings highlight the importance of recognising older adults as a risk group for sexual victimisation and to study SV independently from other forms of violence in old age. In order to detect signs, prevent, mitigate and respond to SV in older adults, sensitisation of society and capacity building of professionals is needed.

\section{Abbreviations}

aOR: Adjusted odds ratio; BSQ: Behaviourally specific questions; $\mathrm{Cl}$ : Confidence interval; LGBT+: Lesbian gay bisexual transgender plus; SD: Standard deviation; SV: Sexual violence; UN: United Nations; VIF: Variance Inflation Factor; WHO: World Health Organization

\section{Supplementary Information}

The online version contains supplementary material available at https://doi. org/10.1186/s12877-021-02485-3.

Additional file 1: Appendix 1. Detailed outcome measurements sexual victimisation. Appendix 2. Question on assailants of sexual violence. Appendix 3. Question on framing of sexual violence. Appendix 4. Question regarding coercion strategies. Appendix 5. Sociodemographic characteristics of the study population $(n=513)$ compared to the Belgian population of 70 years and older.

\section{Acknowledgements}

The authors would like to thank Lotte De Schrijver and Joke Depraetere for their input during the questionnaire development. Also, we want to thank our interviewers for their time and dedication to our study, and Dr. Howard Ryland for his help with the language editing. Finally, we want to thank all older adults who participated in our study for sharing their stories with us.

\section{Authors' contributions}

Conceptualization: A.N., A.C.I., L.N., M.B., G.L., S.A., C.V, and I.K.; methodology: A.N., A.C.I., L.N., M.B., C.V, and I.K.; training of interviewers: A.N., A.C.I., L.N. and I.K.; validation: A.N., A.C.I., L.N., M.B., G.L., S.A., C.V, and I.K., formal analysis: A.N., B.H, and E.S.; investigation: A.N., A.C.I, and B.H.; writing-original draft preparation: A.N. and A.C.l; writing-review and editing: L.N., B.H., M.B., G.L., S.A., E.S., C.V, and I.K; supervision: L.N., G. L, S. A, C.V., and I.K.; project management: L.N., C.V, and I.K. Project coordination: I.K. All authors have read and agreed to the published version of the manuscript.

\section{Funding}

This research was predominantly supported by the Belgian Federal Science Policy Belgian Research Action through the Interdisciplinary Networks funding scheme, grant number BR/175/A5/UN-MENAMAIS.

CV's contribution was supported in part by the Research Foundation Flanders (FWO) Postdoctoral Fellowship funding scheme, grant numbers $12 \mathrm{C} 0616 \mathrm{~N}, 12 \mathrm{C} 0619 \mathrm{~N}$

\section{Availability of data and materials}

The datasets used and analysed during the current study are available from the corresponding author on reasonable request.

\section{Declarations}

Ethics approval and consent to participate

This study was performed according to the Declaration of Helsinki and received ethical approval from the ethical committee of Ghent University/ University Hospital (Belgian registration number: B670201837542). All participants gave their written informed consent before participating in the study.

\section{Consent for publication}

Not applicable.

\section{Competing interests}

The authors declare no conflict of interest. The funders had no role in the design of the study; in the collection, analyses, or interpretation of data; in the writing of the manuscript, or in the decision to publish the results.

\section{Author details}

${ }^{1}$ International Centre for Reproductive Health, Department of Public Health and Primary Care, Ghent University, Ghent, Belgium. ${ }^{2}$ Department of Psychiatry, Ghent University Hospital, Ghent, Belgium. ${ }^{3}$ CARE-ESPRIst, Études et évaluations, University of Liège, Liège, Belgium. ${ }^{4}$ Psychology of Aging Unit, University of Liège, Liège, Belgium. ${ }^{5}$ School of Social Work and Research Centre on Aging, University of Sherbrooke, Quebec, Canada. ${ }^{6}$ Department of Head and Skin - Psychiatry and Medical Psychology, Ghent University, Ghent, Belgium. ${ }^{7}$ Department of Criminology, Criminal Law and Social Law, Ghent University, Ghent, Belgium. ${ }^{8}$ Research Foundation-Flanders (FWO), Brussels, Belgium.

Received: 30 March 2021 Accepted: 26 August 2021

Published online: 26 October 2021

\section{References}

1. World Health Organization. Violence Against Women. Fact Sheet No. 239. 2017. Available online: http://www.who.int/mediacentre/factsheets/fs239/ en/. Accessed 5 Apr 2018.

2. Prevention of Violence: A Public Health Priority. Proceedings of the FortyNinth World Health Assembly, Geneva, Switzerland, 20-25 May 1996. Geneva: WHO; 1996.

3. World Health Organization. World Report on Violence and Health. WHO Geneva, Switzerland; 2002.

4. Jina R, Thomas LS. Health consequences of sexual violence against women Best Pract Res Clin Obstet Gynaecol. 2013 Feb;27(1):15-26. https://doi.org/1 0.1016/j.bpobgyn.2012.08.012.

5. Rapsey CM, Scott KM, Patterson T. Childhood sexual abuse, polyvictimization and internalizing disorders across adulthood and older age: findings from a 25-year longitudinal study. J Affect Disord. 2019;244:171-9. https://doi.org/10.1016/j.jad.2018.10.095.

6. Ege MA, Messias E, Thapa PB, Krain LP. Adverse childhood experiences and geriatric depression: results from the 2010 BRFSS. Am J Geriatr Psychiatry. 2015 Jan;23(1):110-4. https://doi.org/10.1016/j.jagp.2014.08.014.

7. Bows H. Sexual violence against older people. London, UK: Routledge; 2019. https://doi.org/10.4324/9781315269740.

8. Yon Y, Mikton CR, Gassoumis ZD, Wilber KH. Elder abuse prevalence in community settings: a systematic review and meta-analysis. Lancet Glob Health. 2017;5(2):147-56. https://doi.org/10.1016/\$2214-109X(17)30006-2.

9. Nobels A, Vandeviver C, Beaulieu M, Cismaru-Inescu A, Nisen L, Van Den Noortgate N, et al. "Too Grey to Be True?" sexual violence in older adults: a 
critical interpretive synthesis of evidence. Int J Environ Res Public Health. 2020;17(11):4117.

10. Vandenberk A, Opdebeeck S, Lammertyn F. Geweld en onveiligheidsgevoelens bij ouderen: prevalentie en gevolgen. Leuven, Belgium: KUL; 1998.

11. Pathak N, Dhairyawan $R$, Tariq $S$. The experience of intimate partner violence among older women: a narrative review. Maturitas. 2019;121:63-75. https://doi.org/10.1016/j.maturitas.2018.12.011.

12. Bows $\mathrm{H}$. Sexual violence against older people: a review of the empirical literature. Trauma Violence Abuse. 2018;19(5):567-83. https://doi.org/10.11 $77 / 1524838016683455$

13. Fileborn B. Sexual assault and justice for older women: a critical review of the literature. Trauma Violence Abuse. 2017;18(5):496-507. https://doi.org/1 $0.1177 / 1524838016641666$

14. Nisen L. Linchet S (sous la direction scientifique de Casman, M-T) Étude Sur le Bien-Etre des Personnes de Plus de 70 Ans en Wallonie. Liège, Belgium: Panel Démographie Familiale, Respect Seniors; 2010.

15. Naughton C, Drennan J, Lyons I, Lafferty A, Treacy M, Phelan A, et al. Elder abuse and neglect in Ireland: results from a national prevalence survey. Age Ageing. 2012;41(1):98-103. https://doi.org/10.1093/ageing/afr107.

16. Gil AP, Kislaya I, Santos AJ, Nunes B, Nicolau R, Fernandes AA. Elder abuse in Portugal: findings from the first national prevalence study. J Elder Abuse Negl. 2015;27(3):174-95. https://doi.org/10.1080/08946566.2 014.953659

17. Kissal A, Beser A. Elder abuse and neglect in a population offering care by a primary health care center in Izmir, Turkey. Soc Work Health Care. 2011; 50(2):158-75. https://doi.org/10.1080/00981389.2010.527570.

18. Kulakci Altintas H, Korkmaz AG. Prevalence of elder abuse among community-dwelling older adults in Turkey and its associated factors. Psychogeriatrics. 2020;13(20):3-10. https://doi.org/10.1111/psyg.12446.

19. Luoma M-L, Koivusilta M, Lang G, Enzenhofer E, De Donder L, Verté D, et al. Prevalence Study of Abuse and Violence against Older Women: Results of a Multi-Cultural Survey in Austria, Belgium, Finland, Lithuania, and Portugal (European Report of the AVOW Project). Helsinki: National Institute for Health and Welfare (THL); 2011.

20. McMahon S. Changing Perceptions of Sexual Violence Over Time. National Online Resource Centre on Violence Against Women (VAW net). 2011.

21. Gelstrophe L, Larrauri E. Gender and Crime in Europe. In The Routlegde Handbook of European Criminology. Editors S Body-Gendrot, M Hough, K Kerezsi, R Lévy, S Snacken, (Eds.), Routledge: London, UK, 2013; Chapter 11; pp. 188-203.

22. World Health Organization. Sexuality Education Policy Brief No. 1. Geneva: WHO; 2016.

23. Gewirtz-Meydan A, Hafford-Letchfield T, Benyamini Y, Phelan A, Jackson J, Ayalon L. Ageism and sexuality. Chapter 10 In: Contemporary Perspectives on Ageism. Editors L Ayalon, C Tesch-Römer (Eds.), Springer; Cham, 2018. p. 149-162.

24. Bodner E, Palgi Y, Wyman MF. Ageism in Mental Health Assessment and Treatment of Older Adults. Chapter 15 In: Contemporary Perspectives on Ageism. Editors L Ayalon, C Tesch-Römer (Eds.), Springer; Cham, 2018. p. 241-262.

25. Hughes TL, Johnson T, Wilsnack SC. Sexual assault and alcohol abuse: a comparison of lesbians and heterosexual women. J Subst Abuse. 2001;13(4): 515-32. https://doi.org/10.1016/S0899-3289(01)00095-5.

26. Gott M, Hinchliff S, Galena E. General practitioner attitudes to discussing sexual health issues with older people. Soc Sci Med. 2004;58(11):2093-103. https://doi.org/10.1016/j.socscimed.2003.08.025.

27. Saunamäki N, Engström M. Registered nurses' reflections on discussing sexuality with patients: responsibilities, doubts and fears. J Clin Nurs. 2014; 23(3-4):531-40. https://doi.org/10.1111/jocn.12155.

28. Goldblatt H, Band-Winterstein T, Lev S, Harel D. "Who Would Sexually Assault an 80-Year-Old Woman?" Barriers to Exploring and Exposing Sexual Assault Against Women in Late Life. J Interpers Violence. 2020. https://doi. org/10.1177/0886260520934440.

29. United Nations. The sustainable development goals report. 2016. Available from: https://unstats.un.org/sdgs/report/2016/Overview/. Accessed 29 Apr 2019.

30. Nobels A, Vandeviver C, Beaulieu M, Lemmens G, Keygnaert I. Are older women forgotten in the fight against sexual violence? Lancet Glob Health. 2018;6(4):e307. https://doi.org/10.1016/S2214-109X(18)30074-3.

31. CIUSSS West-Central Montreal; elder mistreatment helpline (LAAA); research chair on mistreatment of older adults; Ministère de la Famile, Secrétariat aux aînés, Gouvernement du Québec. Leading Practice to Counter the Mistreatment of Older Adults. Montreal, Québec, Canada, 2017.

32. Schapanksy E, Depraetere J, Keygnaert I, Vandeviver C. Prevalence and Risk factors of Sexual Victimisation: Findings from a National Representative Sample of Belgian Adults Aged 16-69. Int J Environ Res Public Health. 2021; 18(14):7360.

33. Depraetere J, Cismaru-Inescu A, De Schrijver L, Nobels A, Keygnaert I, Vandeviver C. Measuring Sexual Victimisation and Perpetration in Today's Society: Modifications to the Sexual Experience Survey. SocArXiv [Preprint] 2020. Available from: https:/osf.io/preprints/socarxiv/cgevu/ [cited 22 Feb 2020].

34. Nobels A, Cismaru-Inescu I, Nisen L, Hahaut B, Lemmens G, Vandeviver C, Keygnaert I. Challenges in conducting sexual health and violence research in older adults beyond the General Data Protection Regulation: a Belgian case study. J Interpers Violence. 2021:1-21. https://doi.org/10.1177/08862 605211015256 .

35. Depraetere J, Vandeviver C, Vander Beken T, Keygnaert I. Big boys don't cry: a critical interpretive synthesis of male sexual victimization. Trauma Violence Abuse. 2018;21(5):991-1010. https://doi.org/10.1177/1524838018816979.

36. Koss MP, Gidycz CA. Sexual experiences survey: reliability and validity. J Consult Clin Psychol. 1985;53(3):422-3. https://doi.org/10.1037/0022-006X. 53.3.422.

37. Krahé B, Berger A, Vanwesenbeeck I, Bianchi G, Chliaoutakis J, FernándezFuertes AA, et al. Prevalence and correlates of young people's sexual aggression perpetration and victimisation in 10 European countries: a multilevel analysis. Cult Health Sex. 2015;17(6):682-99. https://doi.org/10.1080/13 691058.2014.989265.

38. Keygnaert I, Dias SF, Degomme O, Deville W, Kennedy P, Kovats A, et al. Sexual and gender-based violence in the European asylum and reception sector: a perpetuum mobile? Eur J Public Health. 2015 Feb;25(1):90-6. https://doi.org/10.1093/eurpub/cku066.

39. Lewis-Beck M, Bryman AE, Liao TF. Random Walk. In: Lewis-Beck MS, Bryman A, Futing Liao T, editors. The Sage encyclopedia of social science research methods. Sage Publications, London, UK; 2003.

40. World Health Organization. Ethical and Safety Recommendations for Intervention Research on Violence Against Women: Building on lessons from the WHO publication Putting women first: ethical and safety recommendations for research on domestic violence against women. Geneva, Switserland: WHO; 2016.

41. Piolino P, Desgranges B, Benali K, Eustache F. Episodic and semantic remote autobiographical memory in ageing. Memory. 2002;10(4):239-57. https://doi. org/10.1080/09658210143000353.

42. Charles ST, Mather M, Carstensen LL. Aging and emotional memory: the forgettable nature of negative images for older adults. J Exp Psychol Gen. 2003;132(2):310-24. https://doi.org/10.1037/0096-3445.132.2.310.

43. Fernandes M, Ross M, Wiegand M, Schryer E. Are the memories of older adults positively biased? Psychol Aging. 2008;23(2):297-306. https://doi. org/10.1037/0882-7974.23.2.297.

44. Chen E, Turiano NA, Mroczek DK, Miller GE. Association of reports of childhood abuse and all-cause mortality rates in women. JAMA Psychiat. 2016;73(9):920-7. https://doi.org/10.1001/jamapsychiatry.2016.1786.

45. Felitti VJ, Anda RF, Nordenberg D, Williamson DF, Spitz AM, Edwards V, et al. Relationship of childhood abuse and household dysfunction to many of the leading causes of death in adults: the adverse childhood experiences (ACE) study. Am J Prev Med. 1998;14(4):245-58. https://doi.org/10.1016/S0749-3 797(98)00017-8

46. Brozowski K, Hall DR. Aging and risk: physical and sexual abuse of elders in Canada. J Interpers Violence. 2010;25(7):1183-99. https://doi.org/10.1177/ 0886260509340546.

47. World Health Organization. Global and regional estimates of violence against women: prevalence and health effects of partner violence and sexual non-partner violence. Geneva, Switzerland: WHO; 2013.

48. Erlingsson CL, Saveman Bl, Berg AC. Perceptions of elder abuse in Sweden: voices of older persons. Brief Treat Crisis Interv. 2005;5(2):213-27. https://doi. org/10.1093/brief-treatment/mhi017.

49. Macdowall W, Gibson LJ, Tanton C, Mercer CH, Lewis R, Clifton S, et al. Lifetime prevalence, associated factors, and circumstances of non-volitional sex in women and men in Britain: findings from the third National Survey of sexual attitudes and lifestyles (Natsal-3). Lancet. 2013;382(9907):1845-55. https://doi.org/10.1016/S0140-6736(13)62300-4.

50. Bows $\mathrm{H}$. The other side of late-life intimacy? Sexual violence in later life. Australas J Ageing. 2020;39(S1):65-70. https://doi.org/10.1111/ajag.12728. 
51. Ahnlund P, Andersson T, Snellman F, Sundström M, Heimer G. Prevalence and correlates of sexual, physical, and psychological violence against women and men of 60 to 74 years in Sweden. J Interpers Violence. 2017:123. https://doi.org/10.1177/0886260517696874.

52. Pillemer K, Finkelhor $D$. The prevalence of elder abuse: a random sample survey. Gerontologist. 1988;28(1):51-7. https:/doi.org/10.1093/geront/28.1.51.

53. Melchiorre MG, Di Rosa M, Lamura G, Torres-Gonzales F, Lindert J, Stankunas $M$, et al. Abuse of older men in seven European countries: a multilevel approach in the framework of an ecological model. PLoS One. 2016;11(1): e0146425. https://doi.org/10.1371/journal.pone.0146425.

54. Hillman J. Intimate partner violence among older LGBT adults: Unique risk factors, issues in reporting and treatment, and recommendations for research, practice, and policy. In: Russel B, editor. Intimate Partner Violence and the LGBT+Community. Cham, Switzerland: Springer; 2020. p. 237-54.

55. Canan SN, Jozkowski KN, Wiersma-Mosley J, Blunt-Vinti H, Bradley M. Validation of the sexual experience survey-short form revised using lesbian, bisexual, and heterosexual Women's narratives of sexual violence. Arch Sex Behav. 2020;49(3):1067-83. https://doi.org/10.1007/s1 0508-019-01543-7.

\section{Publisher's Note}

Springer Nature remains neutral with regard to jurisdictional claims in published maps and institutional affiliations.

Ready to submit your research? Choose BMC and benefit from:

- fast, convenient online submission

- thorough peer review by experienced researchers in your field

- rapid publication on acceptance

- support for research data, including large and complex data types

- gold Open Access which fosters wider collaboration and increased citations

- maximum visibility for your research: over $100 \mathrm{M}$ website views per year

At BMC, research is always in progress.

Learn more biomedcentral.com/submissions 